\title{
Influence of Manufacturing Conditions on Inclusion Characteristics and Mechanical Properties of FeCrNiMnCo Alloy
}

\author{
Nuri Choi ${ }^{1}$, Nokeun Park ${ }^{2}$, , Jin-kyung Kim ${ }^{1}$, Andrey V. Karasev ${ }^{3}$, Pär G. Jönsson ${ }^{3}$ (D) \\ and Joo Hyun Park 1,3,*(D) \\ 1 Department of Materials Science and Chemical Engineering, Hanyang University, Ansan 15588, Korea; \\ jace@naver.com (N.C.); jinkyungkim@hanyang.ac.kr (J.-k.K.) \\ 2 School of Materials Science and Engineering, Yeungnam University, Gyeongbuk 38541, Korea; \\ nokeun_park@yu.ac.kr \\ 3 Department of Materials Science and Engineering, KTH Royal Institute of Technology, \\ 10044 Stockholm, Sweden; karasev@kth.se (A.V.K.); parj@kth.se (P.G.J.) \\ * Correspondence: basicity@hanyang.ac.kr; Tel.: +82-31-400-5230
}

Received: 1 August 2020; Accepted: 23 September 2020; Published: 25 September 2020

\begin{abstract}
Three CoCrFeMnNi high-entropy alloys (HEAs) were produced by vacuum induction melting, induction melting under inert gas atmosphere, and melting under inert gas atmosphere followed by air exposure, respectively. The different manufacturing conditions for the three investigated alloys resulted in different levels and types of inclusions. The alloys melted under vacuum or inert gas contained $\mathrm{Al}_{2} \mathrm{O}_{3}$ inclusions formed by impurity $\mathrm{Al}$, due to its high oxidation tendency. The molten alloy exposed in air showed an excessive oxidation. During oxidation of the molten alloy in air, impurity $\mathrm{Al}$ was initially oxidized, and fine $\mathrm{MnCr}_{2} \mathrm{O}_{4}$ inclusions were formed rather than pure $\mathrm{Al}_{2} \mathrm{O}_{3}$ inclusions. This difference was analyzed based on thermodynamic calculations. Specifically, the influence of impurity content on the inclusion characteristics was investigated for the three HEAs. Moreover, the inclusion characteristics were found to have an influence on mechanical properties of the alloys also. In air-exposed HEA, smaller inclusions were formed, resulting in a higher dislocation density at the matrix/inclusion interface and thus strengthening of the HEA. Thus, it is proposed that atmospheric conditions could be an important factor to control the inclusion characteristics and to form fine inclusion particles, which could improve the mechanical properties of HEAs.
\end{abstract}

Keywords: high-entropy alloy; manufacturing; air exposure; inclusion; mechanical property

\section{Introduction}

High-entropy alloys (HEAs) represent novel alloy systems that comprises several principal elements with equiatomic or near-equiatomic ratios, as well as show simple microstructures with a single phase of face-centered cubic (FCC) or body-centered cubic (BCC) or dual phases consisting of FCC, BCC, B2, etc. [1-4]. Recently, HEAs have received considerable attentions due to their simple microstructures and outstanding mechanical properties. Therefore, previous researchers have focused on the alloy design, thermal stability, microstructure, and mechanical properties of various types of HEAs $[5,6]$.

The previous researchers revealed that the HEAs have possibilities to achieve excellent combinations of strength and ductility compared to conventional structural alloys such as stainless steel, twinning-induced plasticity (TWIP) steels, and transformation-induced plasticity (TRIP) steels [6,7]. The equiatomic FeCrNiMnCo alloy, the most extensively studied HEA, shows a high phase stability 
as a FCC single phase for a wide range of temperatures as well as an excellent strength under cryogenic conditions [2,8-12]. Thus, it is considered as a promising cryogenic material. In addition, the mechanical properties of equiatomic FeCrNiMnCo alloy could be improved by grain refinement according to the Hall-Petch equation [13] and enhanced strain hardening by deformation twinning [14]. Precipitation hardening by a nano-sized $\mathrm{L}_{2}$ phase, $\mathrm{Ni}_{3}(\mathrm{Ti}, \mathrm{Al})$, could further improve the mechanical properties of a FeCrNiCo alloy [15].

Overall, very little research has focused on the inclusion control in HEA, which could affect the microstructures and mechanical properties. Especially, the characteristics of non-metallic inclusion particles have been known to govern properties such as the pit corrosion, fatigue, and fracture behavior of steels and alloys [16-19]. The role of inclusions becomes more important in the production of HEA at an industrial scale. Thus, the characterization of inclusions in HEA can provide essential information on the future commercialization of the alloys. The most recent researchers used vacuum and arc-melting techniques in the manufacturing process of HEA $[9,13,14,20-22]$. The techniques are beneficial to prevent contaminations of impurities, which could be caused by gas. Although there are reports of inclusion formation, in spite of that, vacuum melting has been used [20-25]. In the steel industry, effective melting and refining processes such as slag treatment are used to remove impurities and inclusion particles.

Non-metallic inclusion particles are usually formed by interstitial oxygen, sulfur, and nitrogen atoms present in the melt, which results in the formation of oxide, nitride, or sulfide, and so on. They have various influences on mechanical properties due to their different physical and chemical features such as size, morphology, and composition. It is generally known that oxide particles that have a high hardness could deteriorate the mechanical properties of alloys such as failure and fatigue behavior. This is especially true for ductile metals such as austenitic steels and Ni alloys with an FCC crystal structure [26-31].

Hard inclusions are difficult to deform plastically. Thus, they tend to be divided during rolling with the formation of hard fragments, which could be even more detrimental to the final mechanical properties compared to the effect of original inclusions [32]. In addition, the generation and growth of voids usually occur around hard and brittle inclusions (oxide). These particles, which have different mechanical properties compared to the matrix, show different mechanical responses during deformation [33]. This causes a decline of final strength and ductility. The MnS particles are known to be harder in the form of the type I inclusions (sulfides with an oxide core) compared to the type II inclusions (single sulfides) [34]. MnS inclusions have a low high-temperature hardness and induce anisotropic mechanical properties; due to that, they become elongated [35]. The $\mathrm{MnCr}_{2} \mathrm{O}_{4}$ (spinel structure) inclusion is the representative oxide present in $\mathrm{FeCrNiMnCo}$ alloy, when no other impurities are present in the materials.

$\mathrm{Al}_{2} \mathrm{O}_{3}$ inclusions have also been observed in $\mathrm{FeCrNiMnCo}$ alloy, although the materials were melted under vacuum [21,36]. Licavoli et al. [21] observed $\mathrm{Al}_{2} \mathrm{O}_{3}$ and $\mathrm{SiO}_{2}$ inclusions in a $\mathrm{FeCrNiMnCo}$ alloy produced by vacuum arc remelting (VAR), which contain 40-50 ppm oxygen and 200-250 ppm sulfur. The Mn-, Cr-, and Al-rich oxides were also observed in a FeCrNiMnCo alloy ingot produced by the VAR process in previous research by the present authors [36]. The formed inclusions act as void nucleation sites. Larger inclusions lead to a void nucleation during relatively early stages of the deformation, and smaller inclusions lead to a void nucleation at much larger strains [29].

Furthermore, previous researchers investigated the effect of inclusion sizes on the mechanical properties of HEA. The results showed that the toughness of the alloy degraded as the volume fraction of inclusion increased [37]. The increase of the inclusion size considerably affects the mechanical properties such as the ductility and fatigue behavior of an alloy [26]. Consequently, the volume fraction of inclusions as well as their chemical and structural characteristics are important factors to optimize the mechanical properties of HEA.

In this study, FeCrNiMnCo alloys including $\mathrm{Al}$ impurity with raw materials of a commercial grade of a 99.5 mass \% purity, were manufactured via induction melting under different atmospheres. 
The effect of the atmosphere on the impurity level and consequent inclusion formation were discussed. Finally, the relationship between the inclusion characteristics and mechanical properties of HEA was investigated.

\section{Materials and Methods}

\subsection{Manufacturing of FeCrNiMnCo Alloys by Different Melting and Casting Conditions}

Different melting methods were used to produce the FeCrNiMnCo alloys: vacuum tilt casting for the reference alloy and suction casting after melting via a high-frequency induction furnace. The raw materials with a purity higher than 99.5 mass\% were prepared. Especially, the raw manganese was pre-treated by dipping into $\mathrm{H}_{2} \mathrm{O}_{2}+5 \mathrm{vol} \% \mathrm{H}_{2} \mathrm{SO}_{4}$ solution in order to remove oxides on the surface of manganese flakes. For vacuum tilt casting, metals were prepared in total weight of $150 \mathrm{~g}$, and the melting processes were conducted four to five times to obtain homogeneous composition. Casting was conducted in an air-cooled copper mold.

For the induction melting process, $500 \mathrm{~g}$ of metals were placed into a fused alumina ( 99.9 mass $\%$ ) crucible. Thereafter, a purified $\mathrm{Ar}+3 \mathrm{vol} \% \mathrm{H}_{2}$ gas mixture was prepared to prevent oxidation during melting and casting. The melting was conducted at $1873 \mathrm{~K}$ for $1 \mathrm{~h}$ to obtain a homogeneous composition. For preparing the air-exposed alloy ingot after induction melting, the lid was opened after melting, and the $\mathrm{Ar}+3 \mathrm{vol} \% \mathrm{H}_{2}$ gas flow was stopped. After being exposed to air for $1 \mathrm{~h}$, suction casting was performed. In the remaining text, the FeCrNiMnCo alloys are identified according to the manufacturing methods: (i) VC-HEA for alloy produced via VAR, VAR (VC-HEA represents the HEA melted under VaCuum), (ii) AR-HEA for alloy produced via induction melting under an $\mathrm{Ar}+3 \% \mathrm{H}_{2}$ gas atmosphere, (AR-HEA represents the HEA melted under AR- $\mathrm{H}_{2}$ gas) (iii) AE-HEA for HEA melted under an $\mathrm{Ar}+3 \% \mathrm{H}_{2}$ gas, followed by air exposure(AE-HEA represents the HEA melted under $\mathrm{Ar}-\mathrm{H}_{2}$ gas, followed by Air Exposure treatment).

\subsection{Characterization of FeCrNiMnCo Alloys Manufactured by Different Processes}

All ingots produced from different conditions were homogenized at $1273 \mathrm{~K}$ for $24 \mathrm{~h}$ to obtain a uniform composition, which did not consist of a dendritic microstructure. The homogenized alloy samples were cold-rolled with a reduction rate of $80 \%$ and annealed at $1123 \mathrm{~K}$ for $1 \mathrm{~h}$ to obtain fully recrystallized microstructures that did not contain second phases such as sigma phase or BCC $[3,38,39]$. The chemical compositions of HEA were determined using inductively coupled plasma-atomic emission spectrometry (ICP-AES, ACROS, SPECTRO Analytical Instruments GmbH, Kleve, Germany). The interstitial elements, carbon, sulfur, nitrogen, and oxygen contents were determined using gas combustion analyzers, a carbon/sulfur analyzer (CS800, ELTRA GmbH, Haan, Germany), and a nitrogen/oxygen analyzer (TC-300, LECO Corp., St. Joseph, MI, USA), respectively. The phases of HEA and the oxide layers were identified by X-ray diffraction (XRD) patterns obtained using a D/MAX-2500/PC, Rigaku, Japan.

The non-metallic inclusion particles were characterized using field emission scanning electron microscopy analysis (FE-SEM, MIRA3, TESCAN, Brno, Czech Republic) with an energy dispersive $\mathrm{X}$-ray spectroscope (EDS) at an operating voltage of $15 \mathrm{kV}$. The three-dimensional morphology of inclusions was also observed by FE-SEM after the inclusions were separated from an alloy matrix using the electrolytic extraction method with a $10 \%$ AA solution. For the extraction, a $500 \mathrm{~mA}$ of current was applied for $4 \mathrm{~h}$ (Won Tech, WPG100e, Daejeon, Korea).

The crystallographic structures of the inclusions were investigated by using high-resolution transmission electron microscopy (HR-TEM) imaging by transmission electron microscopy (TEM, JEM 2100F, JEOL, Tokyo, Japan). TEM specimens were produced by focused ion beam (FIB) milling (LYRA1, TESCAN, Czech Republic) and electrolytic polishing. The observation area, including the inclusion particles, was selected from the specimens and was thinned using FIB. Thin foils of thickness 
under $80 \mu \mathrm{m}$ were polished by using jet-polisher with an electrolyte consisting of $10 \% \mathrm{HClO}_{4}$, $90 \%$ methanol at $22.5 \mathrm{~V}$. The polishing temperature was fixed at $261 \mathrm{~K}$.

To investigate the tensile properties of alloy samples, the ASTM (American Society for Testing and Materials) E8 size specimens were cut from the cold-rolled and annealed sheets [40]. Tensile tests were carried out three times for each sample, and the average values were used as the mechanical property values. Standard testing methods of KS B 0802:2003 with a strain rate of $10^{-3} / \mathrm{s}$ was used in an INSTRON testing machine (model 5589, INSTRON, Norwood, MA, USA) at room temperature.

\section{Experimental Results}

\subsection{Impurity Levels Depending upon Manufacturing Processes}

Before considering the difference in the inclusion formation of the HEA, the impurity level affecting the composition of inclusion should be taken into account. Even in the raw materials prepared in high purity above $99.5 \%$, impurities could be introduced to the materials from various routes. In order to verify the type and content of impurities, ICP-AES analyses were conducted for the raw materials, i.e., reagent grade cobalt, chromium, iron, manganese, and nickel. The results are summarized in Table 1. Aluminum, silicon, and selenium were detected to be included in $\mathrm{Co}, \mathrm{Cr}$, and to some small extent in Ni. Especially, 0.33 mass $\% \mathrm{Al}$ was present in $\mathrm{Co}$, which is considered to originate from its manufacturing process, i.e., an aluminothermic reduction of Co-oxide to $\mathrm{Co}\left(3 \mathrm{CoO}+2 \mathrm{Al}=3 \mathrm{Co}+\mathrm{Al}_{2} \mathrm{O}_{3}\right)$ [41]. An aluminothermic reaction is also used in the chromium manufacturing process, and a silicothermic reaction could be used to produce commercial ferrochromium alloys [42,43]. Thus, $\mathrm{Al}$, Si impurities could be detected, which are inevitable for commercial-grade pure metals. Selenium is known to be present in electrolytic manganese due to its usage as an electrolyte additive in manufacturing process [44,45]. Those impurities in the raw materials remain in the alloy after melting without a cleaning-refining step, and they also remain in the manufactured final alloys.

Table 1. Impurity content in the raw materials (mass ppm).

\begin{tabular}{cccc}
\hline Raw Material & Al & Si & Se \\
\hline Cobalt & 3300 & 60 & - \\
Chromium & 680 & 1600 & - \\
Iron & - & - & - \\
Manganese & - & - & 650 \\
Nickel & 30 & 30 & - \\
\hline
\end{tabular}

The same chemical analysis was carried out on the manufactured HEA for verification of the chemical homogeneity and impurity contents. The chemical composition of the principal elements and interstitial impurity levels of the HEA are listed in Table 2. An exposure in air of AE-HEA caused an excessive oxidation of elements and especially of Mn. However, all of the elements were within the range of \pm 1.0 mass $\%$. This fluctuation of composition did not influence the phase stability of HEA and all alloys contained a FCC single phase $[39,46]$, as determined based on the XRD patterns.

Variations in atmospheric conditions also had an influence on impurity content. In VC-HEA and AR-HEA, where no oxidation occurred, the Al contents were hundreds of ppm. When the alloy melt was exposed to air, the $\mathrm{Al}$ content remarkably decreased to $10-20 \mathrm{ppm}$, as $\mathrm{Al}$ has a high oxidation tendency. The preferential oxidation of $\mathrm{Al}$ rather than $\mathrm{Mn}$ and $\mathrm{Cr}$ can be easily understood based on the Ellingham diagram [47]. Carbon shows no significant difference according to atmospheric conditions and neither does sulfur, except for VC-HEA. Meanwhile, the contents of nitrogen and oxygen in AE-HEA rapidly increased by the dissolution of air $\left(\mathrm{N}_{2}\right.$ and $\left.\mathrm{O}_{2}\right)$ into the melt. 
Table 2. Chemical composition of principal elements and impurity level of the alloys.

\begin{tabular}{ccccccccccc}
\hline \multirow{2}{*}{ Alloys } & \multicolumn{4}{c}{$\leftarrow$ Alloy Elements, Mass\% (at\%) $\rightarrow$} & \multicolumn{4}{c}{$\leftarrow$ Impurities, Mass ppm $\rightarrow$} \\
& Fe & Cr & Ni & Mn & Co & Al & C & S & N & O \\
\hline \multirow{2}{*}{ VC-HEA } & 20.2 & 17.6 & 21.3 & 19.6 & 21.3 & 340 & 72 & 121 & 56 & 35 \\
& $(20.3)$ & $(19.0)$ & $(20.3)$ & $(20.0)$ & $(20.3)$ & $( \pm 60)$ & $( \pm 6)$ & $( \pm 20)$ & $( \pm 4)$ & $( \pm 6)$ \\
\hline \multirow{2}{*}{ AR-HEA } & 20.1 & 17.9 & 21.1 & 19.8 & 21.1 & 230 & 78 & 40 & 120 & 29 \\
& $(20.2)$ & $(19.3)$ & $(20.2)$ & $(20.2)$ & $(20.1)$ & $( \pm 20)$ & $( \pm 8)$ & $( \pm 6)$ & $( \pm 20)$ & $( \pm 8)$ \\
\hline \multirow{2}{*}{ AE-HEA } & 20.9 & 17.6 & 22.0 & 17.5 & 22.0 & 15 & 89 & 37 & 875 & 99 \\
& $(21.0)$ & $(19.0)$ & $(21.0)$ & $(17.9)$ & $(21.0)$ & $( \pm 5)$ & $( \pm 6)$ & $( \pm 6)$ & $( \pm 40)$ & $( \pm 3)$ \\
\hline
\end{tabular}

\subsection{Characterization of Non-Metallic Inclusions}

In FeCrNiMnCo alloys, $\mathrm{MnCr}_{2} \mathrm{O}_{4}$ spinel, $\mathrm{Al}$ - and Si-rich oxides, $\mathrm{MnS}$ and $\mathrm{Cr}$-rich $\mathrm{M}_{23} \mathrm{C}_{6}$ particles have been reported to form [11,21,48]. In the present work, oxides including $\mathrm{Mn}, \mathrm{Cr}$, and $\mathrm{Al}$ were observed as the alloys contain $\mathrm{Al}$ as an impurity element. In addition, $\mathrm{Mn}(\mathrm{S}, \mathrm{Se})$ was observed due to the contamination of Mn with Se. The observed inclusions could be classified based on the chemical composition; oxide, sulfur-selenide, and mixed phase (mixed particles with oxide and sulfur-selenide). In VC-HEA and AR-HEA, only $\mathrm{Al}_{2} \mathrm{O}_{3}$ and $\mathrm{Mn}\left(\mathrm{S}\right.$,Se) were found, while $\mathrm{MnCr}_{2} \mathrm{O}_{4}$ without $\mathrm{Al}_{2} \mathrm{O}_{3}$ and $\mathrm{Mn}(\mathrm{S}, \mathrm{Se})$ were observed in AE-HEA. In VC-HEA, $\mathrm{Al}_{2} \mathrm{O}_{3}$ inclusion was formed prior to the formation of $\mathrm{MnCr}_{2} \mathrm{O}_{4}$ in spite of the presence of larger amounts of $\mathrm{Mn}$ and $\mathrm{Cr}$ than that of Al. This is due to higher oxidation tendency of $\mathrm{Al}$ compared to $\mathrm{Cr}$ and $\mathrm{Mn}$.

TEM analyses were conducted to investigate crystal structures and the chemical compositions of the observed inclusions. The bright field (BF) TEM images, diffraction patterns (DPs), and EDS spectra of the observed inclusions are shown in Figure 1. The diffraction patterns were obtained from the same inclusions by the tilting TEM stage. Figure 1a shows the BF TEM image, DPs, and the EDS spectrum of a $\mathrm{MnCr}_{2} \mathrm{O}_{4}$ spinel, as observed in AE-HEA. The measured composition of the spinel is $\mathrm{Mn}_{14.5} \mathrm{Cr}_{28.8} \mathrm{O}_{56.7}$ (at\%). The detected Cu peak in the EDS spectrum originated from a copper grid used for TEM analysis. The space group of the spinel is $\mathrm{Fd} 3 \mathrm{~m}$ (227), with a lattice parameter of $8.437 \AA$, which agrees with XRD data. In Figure $1 b, \alpha-\mathrm{Al}_{2} \mathrm{O}_{3}$ (corundum) observed in AR-HEA is known as a hexagonal crystal system, the space group of $R 3 c(167)$, and a lattice parameter of $a=4.762 \AA$, $c=12.991 \AA$, according to XRD data. The observed diffraction patterns coincide with it. Minor contents of $\mathrm{Mn}$ and $\mathrm{Cr}$ below 1 at\% were detected. As shown in Figure 1c, the structure type of $\mathrm{Mn}(\mathrm{S}, \mathrm{Se})$ observed in AR-HEA was clarified as an $\alpha$-MnS, cubic structure belonging to space group Fm $\overline{3} \mathrm{~m}$ and with a lattice parameter of $5.226 \AA$. This inclusion is a solid solution consisting of MnS and MnSe.
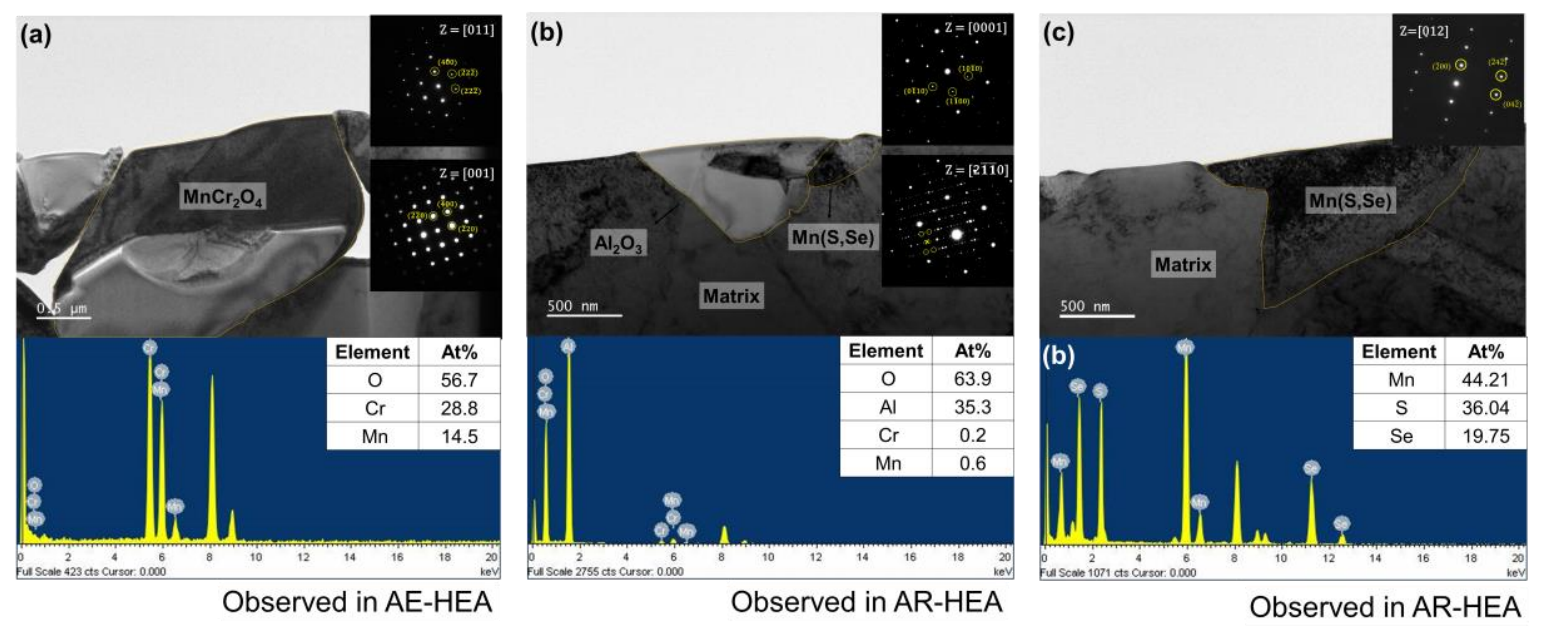

Figure 1. Crystallographic features of (a) $\mathrm{MnCr}_{2} \mathrm{O}_{4}$, (b) $\mathrm{Al}_{2} \mathrm{O}_{3}$, and (c) $\mathrm{Mn}(\mathrm{S}, \mathrm{Se})$. 
The representative two- and three-dimensional morphology, size, and composition of each type of inclusion in HEA are shown in Figure 2. The chemical compositions of inclusions were determined based on EDS peaks for the three-dimensional investigation of particles on a film filter and were classified as shown in Figure 2i-k. The morphologies were observed by SEM images. Two-dimensional morphologies of inclusions are shown in Figure $2 \mathrm{a}, \mathrm{c}, \mathrm{e}, \mathrm{g}, \mathrm{h}$. Three-dimensional morphologies are shown in Figure $2 b, d, f$, and they provide more accurate information about the shape of inclusions. In addition, single phase particles such as $\mathrm{MnCr}_{2} \mathrm{O}_{4}$ and $\mathrm{Mn}(\mathrm{S}, \mathrm{Se})$ in sizes between 1 and $3 \mu \mathrm{m}$ and relatively smaller $\mathrm{Al}_{2} \mathrm{O}_{3}$ or mixed phase particles were formed. Furthermore, $\mathrm{Al}_{2} \mathrm{O}_{3}$ particles observed in VC-HEA were coarser than those in AR-HEA.
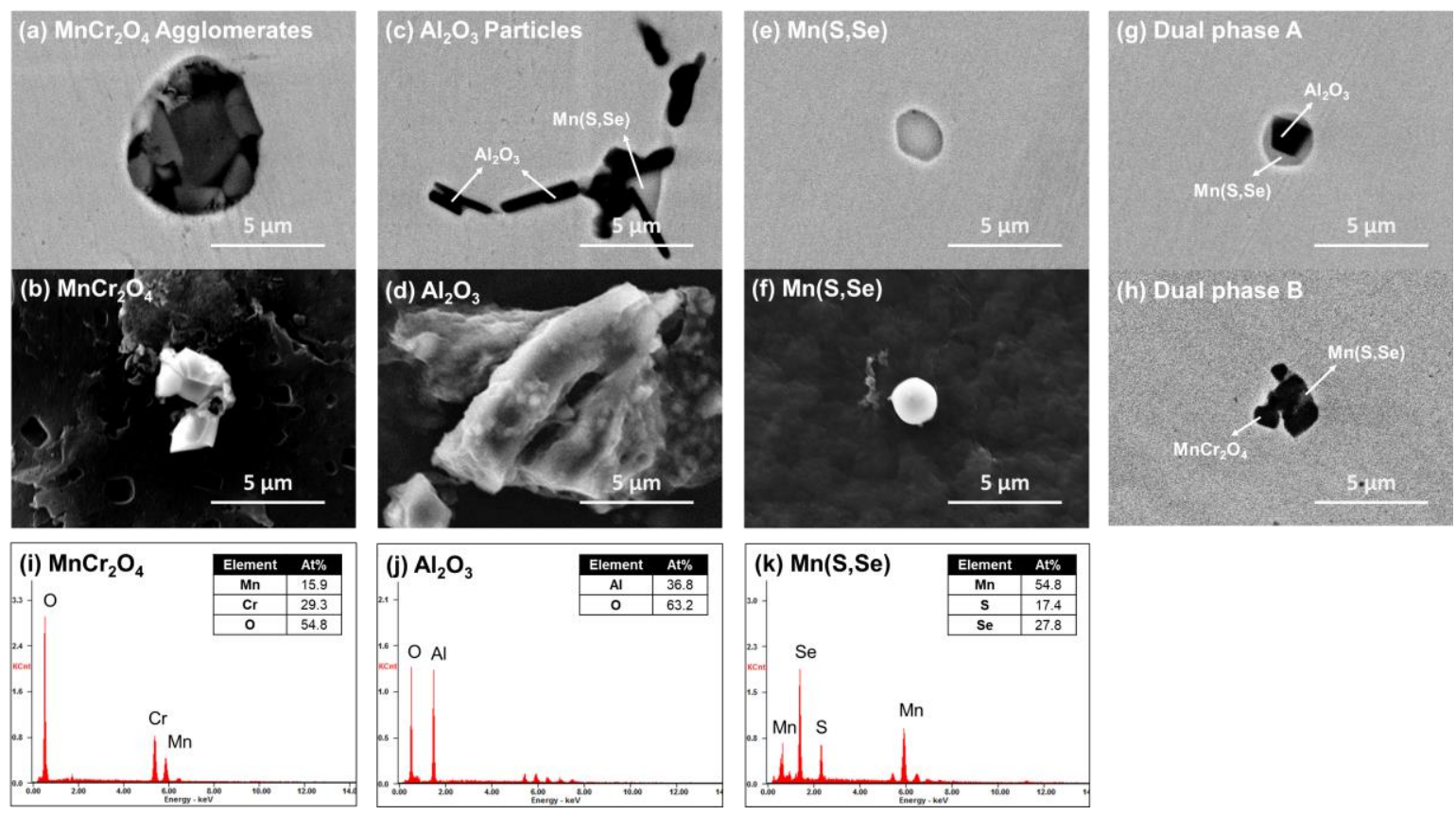

Figure 2. Representative morphologies and chemical composition for types of inclusions. (a,c,e,g,h) 2D and $(\mathbf{b}, \mathbf{d}, \mathbf{f}) 3 \mathrm{D}$ morphologies, and (i-k) energy dispersive $\mathrm{X}$-ray spectroscope (EDS) peaks.

During manufacturing AE-HEA, oxidation by air caused the formation of an oxide layer on top of the melt. This is shown in Figure 3a, which is a cross-sectional image of the crucible. The oxide layer is formed on the melt surface, and it separates from metal after solidification. The elements and phases composing the oxide layer were determined by using XRD patterns and EDS mapping. The phases composing the oxide layer were determined as $\mathrm{AB}_{2} \mathrm{O}_{4}$ spinel $(\mathrm{A}=\mathrm{Mn}$ and $\mathrm{B}=\mathrm{Cr})$ and $\mathrm{Al}_{2} \mathrm{O}_{3}$ according to XRD patterns and EDS mapping, as shown in Figure $3 b, c$. These results correspond with the chemical analysis from ICP-AES (Table 2), where the contents of Al and Mn decreased compared to VC-HEA and AR-HEA samples. During the experiment, it was verified that the $\mathrm{Al}$ content decreases as the exposure time to air increases, as shown in Figure 3d.

Due to the formation of an oxide layer, AE-HEA contains less aluminum than VC-HEA and AR-HEA. This difference in chemical composition has an influence on the inclusion formation thermodynamics. The equilibrium oxide phase diagram at the melting temperature $(1873 \mathrm{~K})$ was investigated using the thermochemical computing software (FactSage ${ }^{\mathrm{TM}}$ version 7.3, GTT-Technologies, Germany and ThermFact Ltd., Canada) based on the Gibbs energy minimization principle, as shown in Figure 4. This provides the stable oxide phases in the FeCrNiMnCo alloy melt containing aluminum and oxygen. This kind of phase stability diagram is widely used to predict the composition of non-metallic inclusions in molten steels [49-53]. 

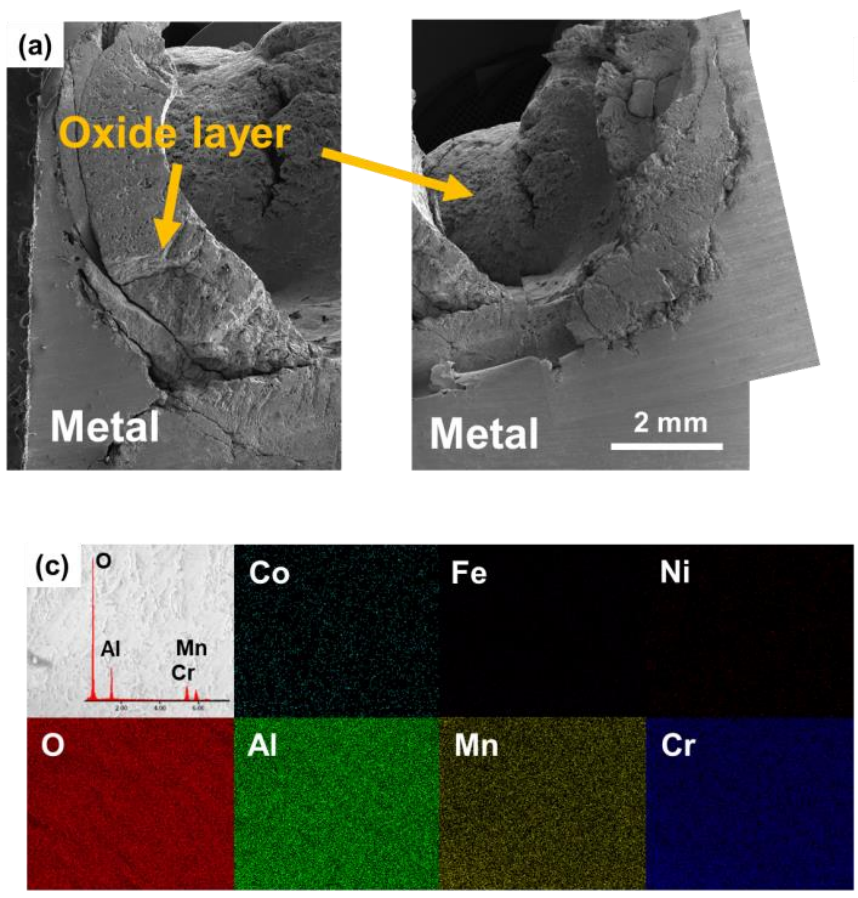

A A

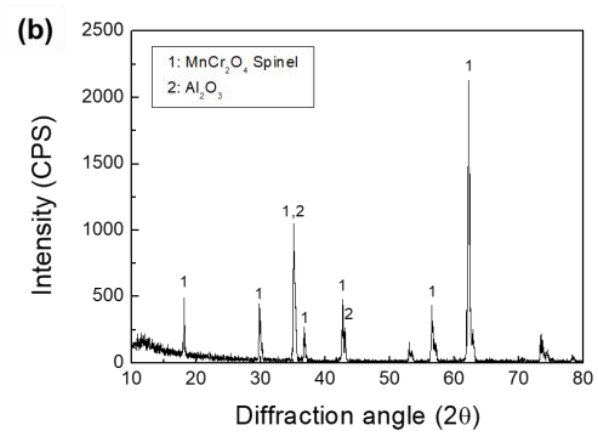

(d)

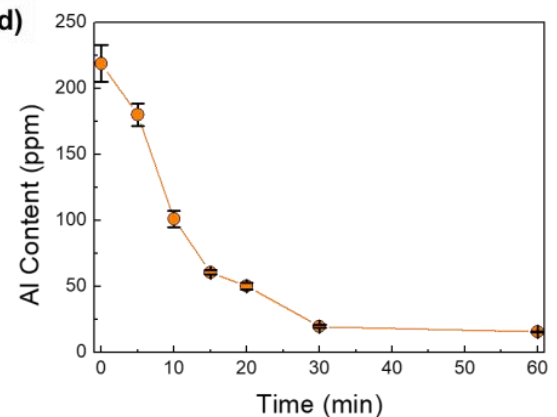

Figure 3. The oxide layer formed due to air exposure during the manufacturing of AE-HEA. (a) Macroscopic images of the oxide layer after the experiment, (b) XRD patterns of the layer,

(c) EDS mapping images of the layer, and (d) Al content in the melt according to air exposure time.

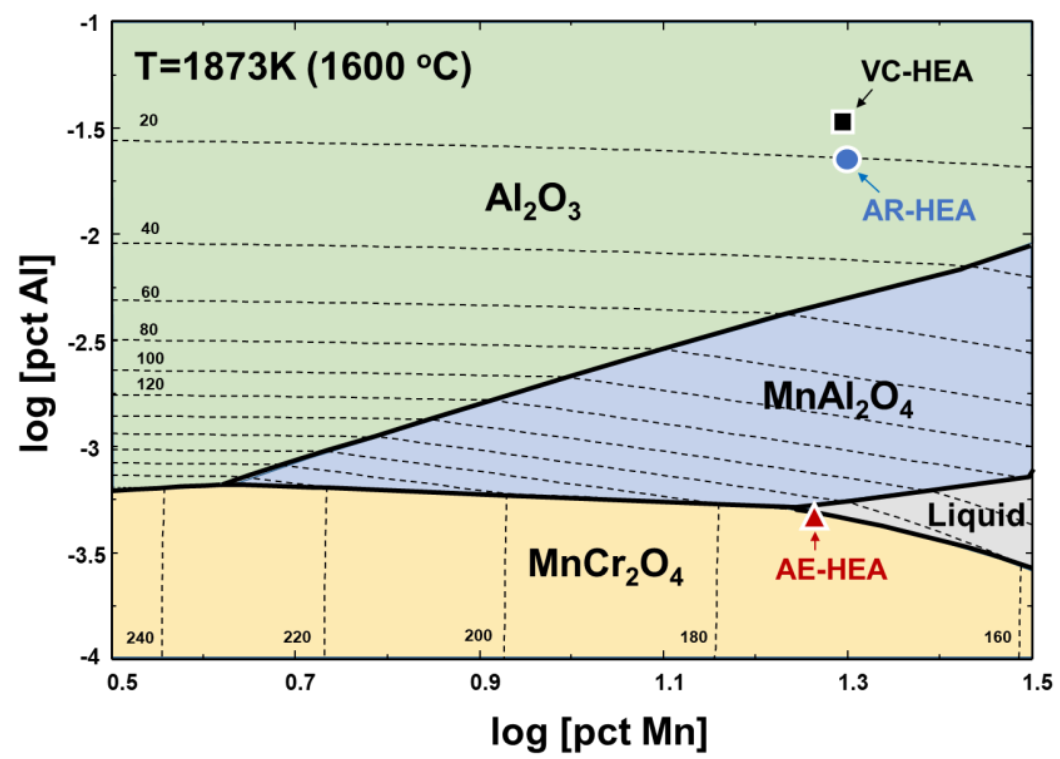

Figure 4. Phase stability diagram of $\mathrm{MnCr}_{2} \mathrm{O}_{4}, \mathrm{MnAl}_{2} \mathrm{O}_{4}$, and $\mathrm{Al}_{2} \mathrm{O}_{3}$ at $1873 \mathrm{~K}$. Black, blue, and red dots indicate VC-HEA, AR-HEA, and AE-HEA, respectively.

In the present HEA system, oxide phases such as $\mathrm{MnCr}_{2} \mathrm{O}_{4}, \mathrm{MnAl}_{2} \mathrm{O}_{4}$, and $\mathrm{Al}_{2} \mathrm{O}_{3}$ are formed in the molten alloy. Aluminum participates in oxide formations over a wide range of concentrations. The dashed lines (and numbers) represent the equilibrium oxygen concentration (ppm) in molten alloy according to the $\mathrm{Mn}$ and $\mathrm{Al}$ concentrations. The contents of $\mathrm{Mn}$ and $\mathrm{Al}$ in VC-HEA, AR-HEA, and AE-HEA are given in Figure 4. The stable oxide in VC-HEA and AR-HEA melts at $1873 \mathrm{~K}$ is $\mathrm{Al}_{2} \mathrm{O}_{3}$ rather than $\mathrm{MnCr}_{2} \mathrm{O}_{4}$ or $\mathrm{MnAl}_{2} \mathrm{O}_{4}$, whereas the $\mathrm{Mn}$ and $\mathrm{Al}$ contents in AE-HEA lie on a phase boundary between liquid and $\mathrm{MnCr}_{2} \mathrm{O}_{4}$. In accordance with thermodynamic calculation, $\mathrm{MnAl}_{2} \mathrm{O}_{4}$ was not found in all HEA samples. 
An air exposure to alloy melt has an influence not only on the chemistry but also on the size distribution of inclusion particles. SEM analyses were carried out in order to evaluate the area fraction of total inclusion particles in each HEA. Here, the observation area was about $0.2 \mathrm{~mm}^{2}$ for each specimen. The area fraction (AF) of inclusions was evaluated in the same way as performed in our previous study [36]. The number densities were 83, 101, and 102 per $\mathrm{mm}^{2}$ for VC-HEA, AR-HEA, and AE-HEA, respectively. However, the $\mathrm{AF}$ values are significantly different according to samples, i.e., $\mathrm{AF}=0.237 \%$, $0.168 \%$, and $0.109 \%$ for VC-, AR-, and AE-HEA, respectively, as shown in Figure 5. Almost all the inclusions in AE-HEA were smaller than $2.5 \mu \mathrm{m}$ (mainly $\mathrm{MnCr}_{2} \mathrm{O}_{4}$ ), while the larger inclusions greater than $4 \mu \mathrm{m}$ (mainly $\mathrm{Al}_{2} \mathrm{O}_{3}$ and mixed type) were present in the VC-HEA and AR-HEA samples.
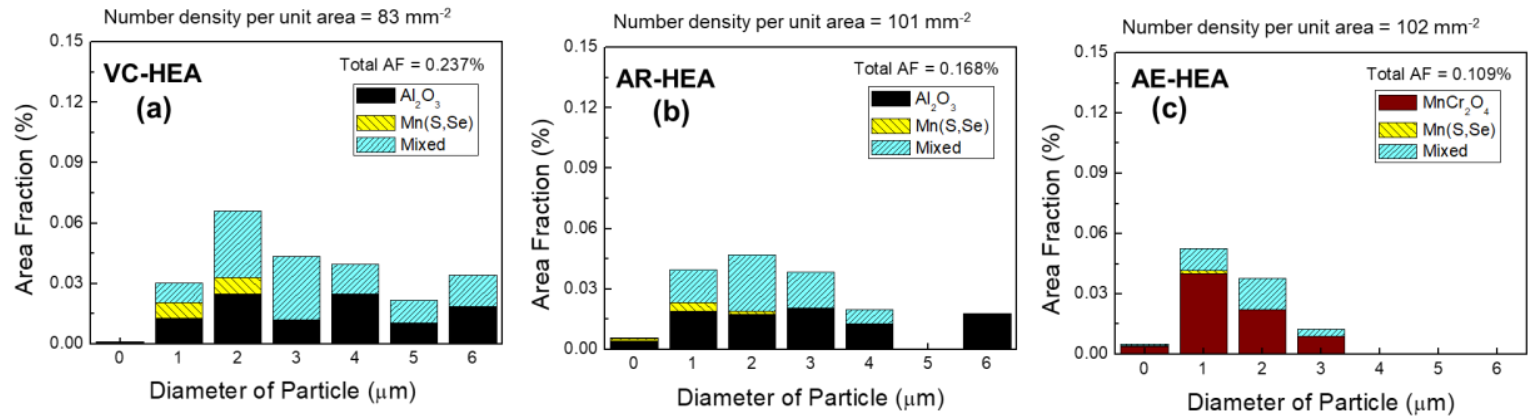

Figure 5. Area fraction of the inclusions classified with type and size in (a) VC-HEA, (b) AR-HEA, and (c) AE-HEA. Total area fraction and number density of inclusions are shown in each alloy system.

In general, the impurity level (IL) is defined as a sum of the interstitial elements content in order to relate the impurity content to the amount of inclusions [54]. In the present study, because major inclusions are Al-rich oxides and sulfide, the content of aluminum, oxygen, and sulfur was summed up as an IL index. The AF of non-metallic inclusions increases linearly with an increasing IL index, as shown in Figure 6. The IL and AF values in AE-HEA are the lowest, while the IL and AF values in VC-HEA are the highest. This is because the oxidation treatment in AE-HEA strongly reduces the impurity $\mathrm{Al}$ content in the alloy melt, resulting in the formation of Al-rich oxide layers in conjunction with the $\mathrm{MnCr}_{2} \mathrm{O}_{4}$ phase. At the same time, the non-metallic inclusions formed in the alloy melt floated up to the melt surface and easily attached to the oxide layer, and they could be easily removed from the alloy after melting and solidification.

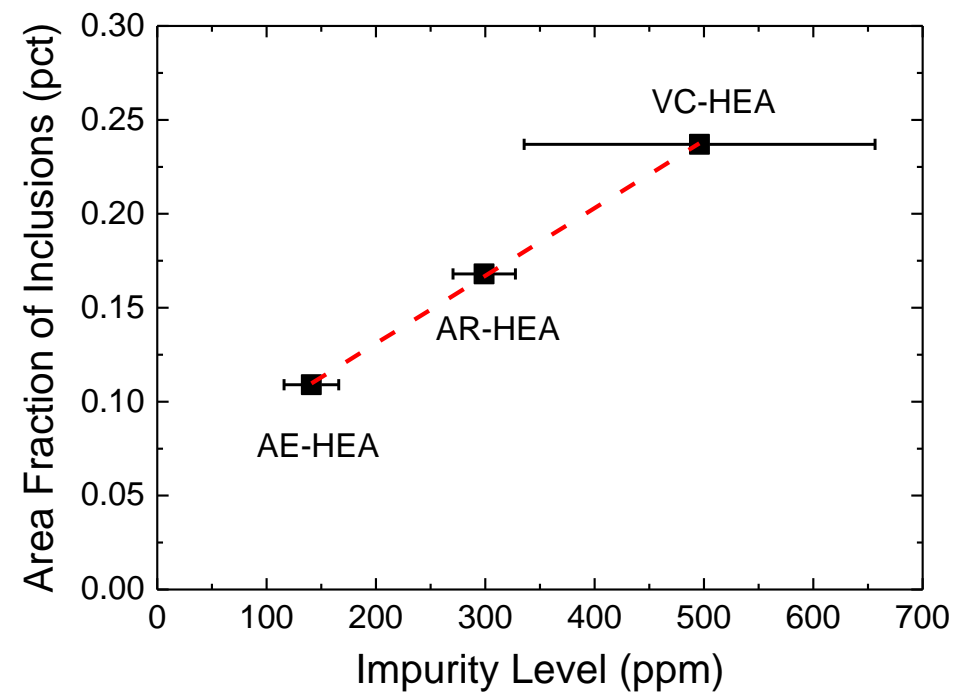

Figure 6. Comparison of area fraction of inclusions for the high-entropy alloys (HEAs) according to impurity level (IL) (IL = Al $+\mathrm{S}+\mathrm{O})$. 


\subsection{Mechanical Properties and Fracture Behavior}

The engineering stress-strain curves of three investigated HEAs after cold-rolling and annealing are shown in Figure 7a. Despite the similar grain sizes of $10( \pm 1.5) \mu \mathrm{m}$ of the three investigated HEAs, the AE-HEA samples show distinctive tensile properties. The VC-HEA and AR-HEA samples exhibit similar yield strengths (YS) and ultimate tensile strengths (UTS), whereas the AE-HEA samples show higher YS and UTS, but lower ductility compared to the other two alloys. The strain hardening rate (SHR) of AE-HEA is slightly higher than those of VC- and AR-HEA, as shown in Figure $7 \mathrm{~b}$.
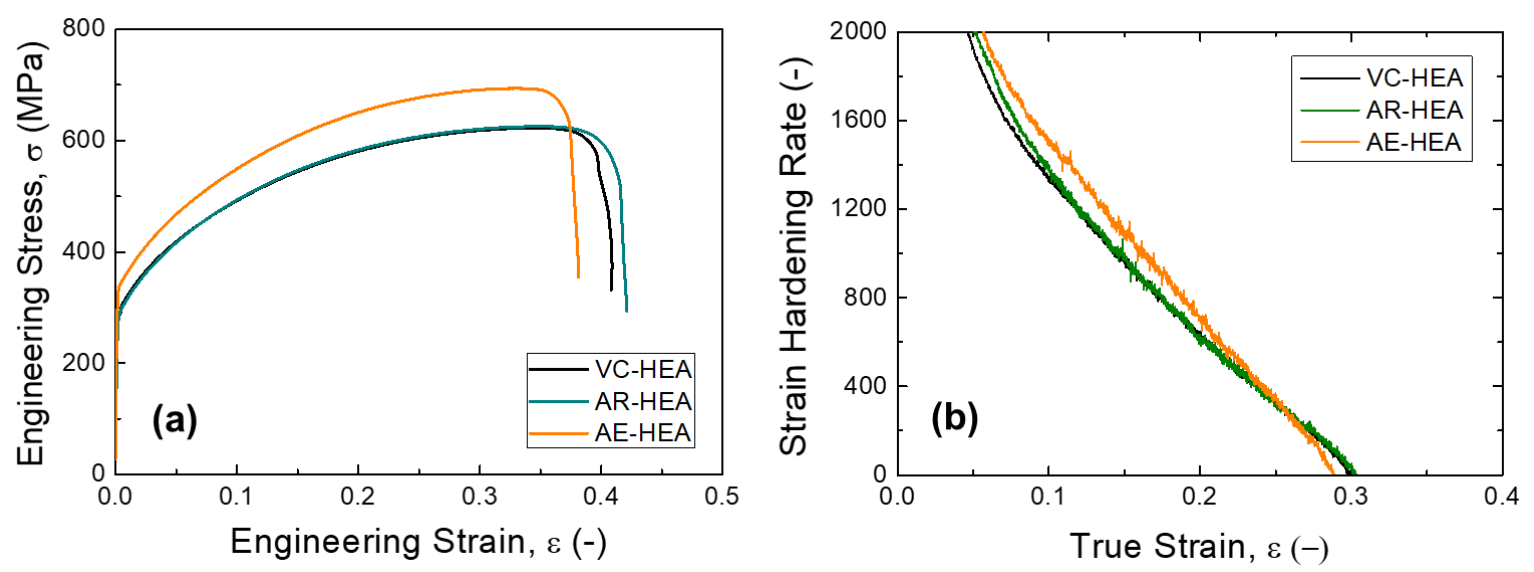

Figure 7. (a) Engineering stress-strain curves and (b) strain-hardening rate curves of HEAs.

Focusing on the fracture of HEA, the fractured surface was observed by using SEM-EDS for each alloy specimen. All the investigated HEAs exhibit ductile fractures with dimples, as shown in Figure 8. In addition, a high density of particles was observed inside the dimples, which indicated a void initiation by particles $[25,55,56]$. The chemical compositions of these particles were confirmed to be $\mathrm{Al}_{2} \mathrm{O}_{3}$ in VC- and AR-HEA samples by using SEM-EDS spectra, while the particles were identified as $\mathrm{MnCr}_{2} \mathrm{O}_{4}$ in AE-HEA.
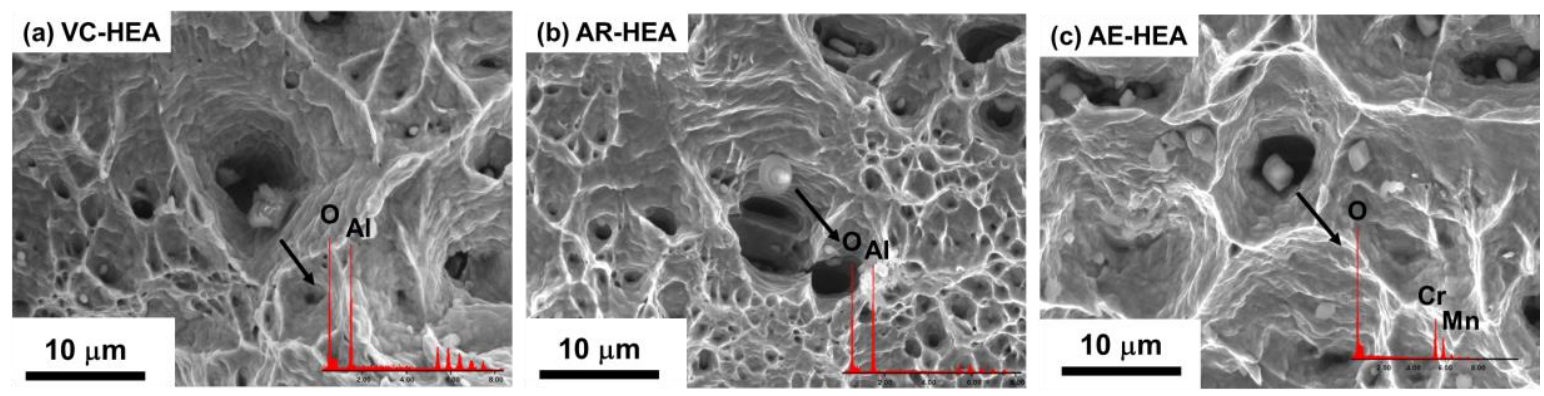

Figure 8. Fractography of (a) VC-HEA, (b) AR-HEA, and (c) AE-HEA. The chemical composition of particles in each dimple are represented with EDS peaks.

\subsection{Microstructural Change upon Tensile Deformation}

The TEM BF images of the cold-rolled and annealed AE-HEA are shown in Figure 9. A relatively low density of dislocations is observed inside the grains, and a higher density of dislocations is often observed at the grain boundaries. In Figure 9a, the white dashed lines represent grain boundaries, while the red arrows indicate dislocations near the grain boundaries. Figure $9 \mathrm{~b}$ shows a high density of partial dislocations, as evidenced by the stacking fault contrast associated with the dislocations, near the grain boundaries. 


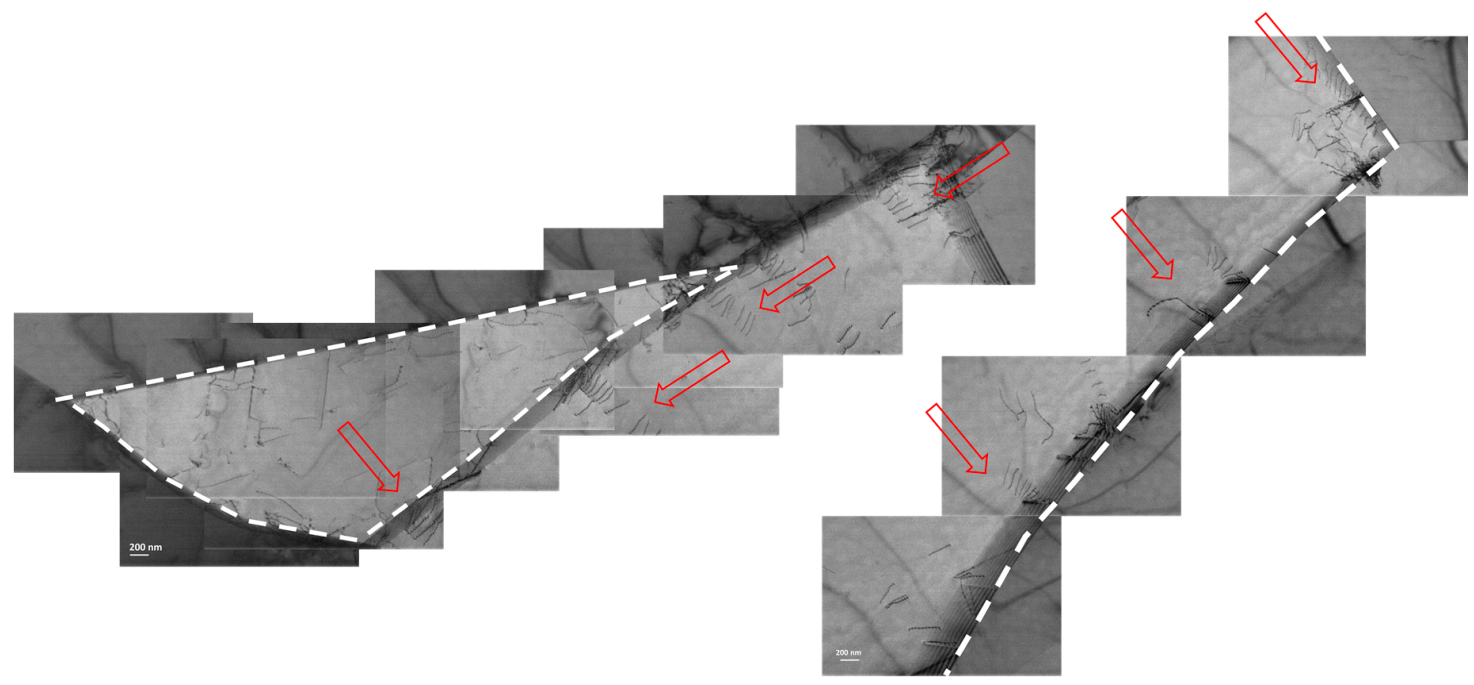

(a)
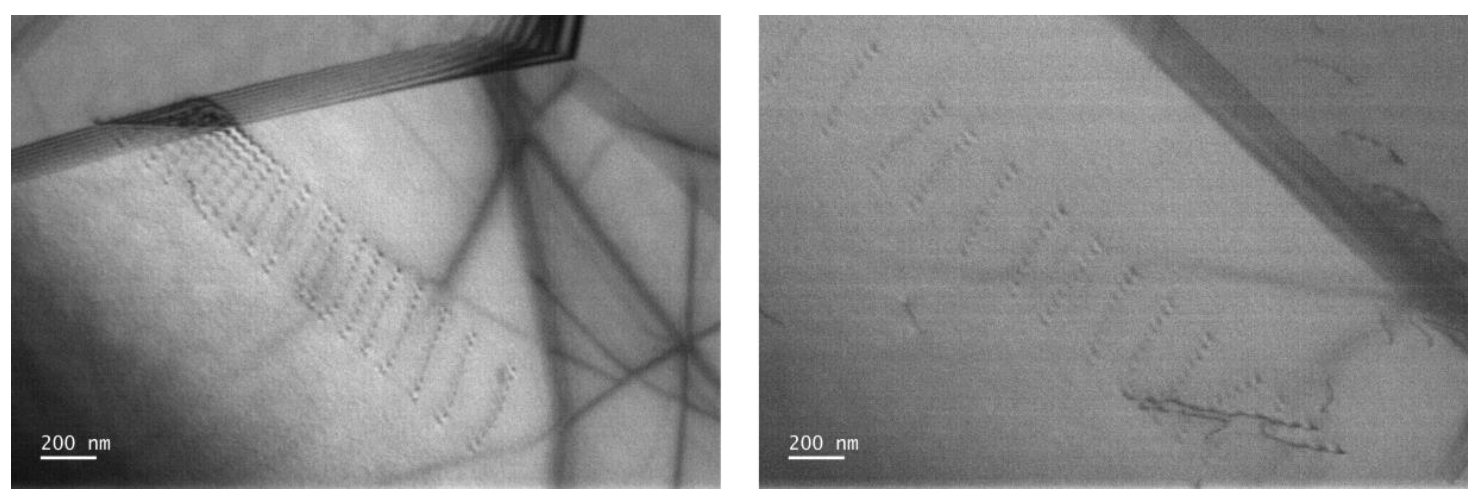

(b)
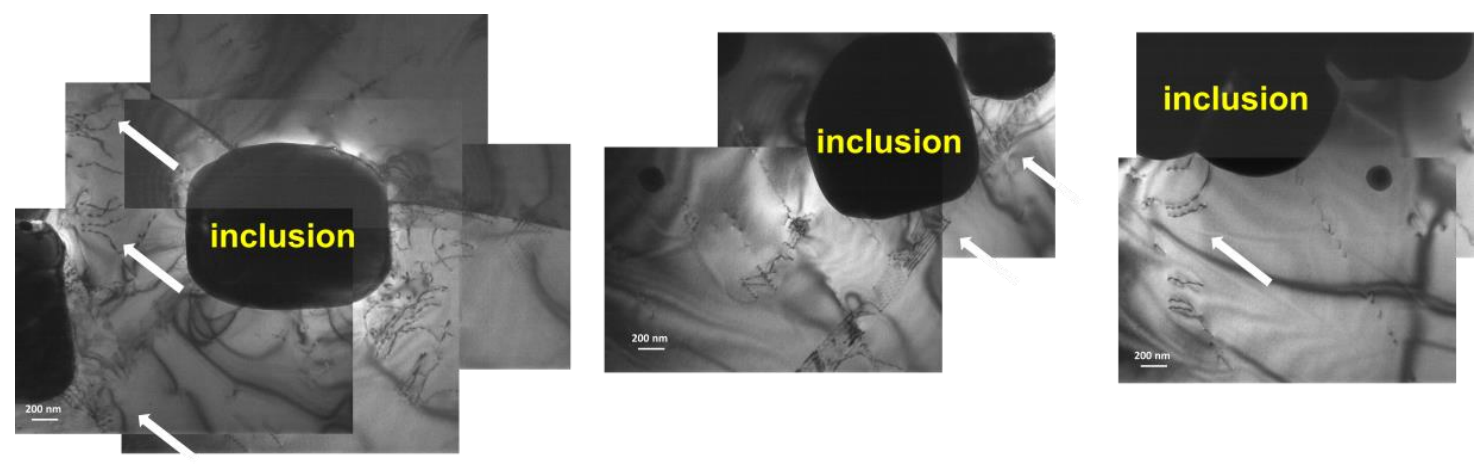

(c)

Figure 9. (a) TEM bright field (BF) images showing a high dislocation density near grain boundaries. (b) Magnified images showing a high dislocation density near grain boundaries. (c) TEM BF image showing dislocation tangling around inclusion particles.

In the dislocation and inclusion theory suggested by Eshelby and Peierls [57,58], when the material has undergone a deformation, the stress field remains in the inclusion and its surroundings. This stress could cause various interactions between dislocations around the inclusion. When the inclusion is rigid in an elastic material, the inclusion tends to repel the screw dislocation. At the same time, the boundary between the matrix and inclusion is impenetrable for dislocations. Consequently, the dislocation movement is stopped at the interface during deformation, and dislocations are entangled. This tendency increases when the size of an inclusion is small, where the curvature of the interface between the 
inclusion and matrix is larger $[59,60]$. This is observed in AE-HEA, where most of the inclusions are small with a size of about $1 \mu \mathrm{m}$. The inclusion particles and dislocation entanglement at the interface between the matrix and inclusion are shown in Figure 9c, wherein the white arrows indicate the dislocation entanglements around inclusion particles. The observed high density of dislocations near the inclusions could lead to an increased yield strength of AE-HEA.

The electron backscatter diffraction (EBSD) deformation microstructures after fracture and misorientation angle distribution of the three investigated alloys are shown in Figure 10. Annealing twins and deformation-induced twins were observed in all specimens (Figure 10a-c). Deformation-induced twins are known to have misorientation angles of about $60^{\circ}$ to $<111>$. The number fraction of each misorientation angle of about $60^{\circ}$ is $4 \%, 3 \%$, and $6 \%$ for VC-HEA, AR-HEA, and AE-HEA, respectively, as shown in Figure 10d-f. This could represent a higher activation of deformation twins in AE-HEA compared to the other two alloys. The higher deformation twinning activity in AE-HEA could result in its higher strain-hardening rate compared to the other two alloys.
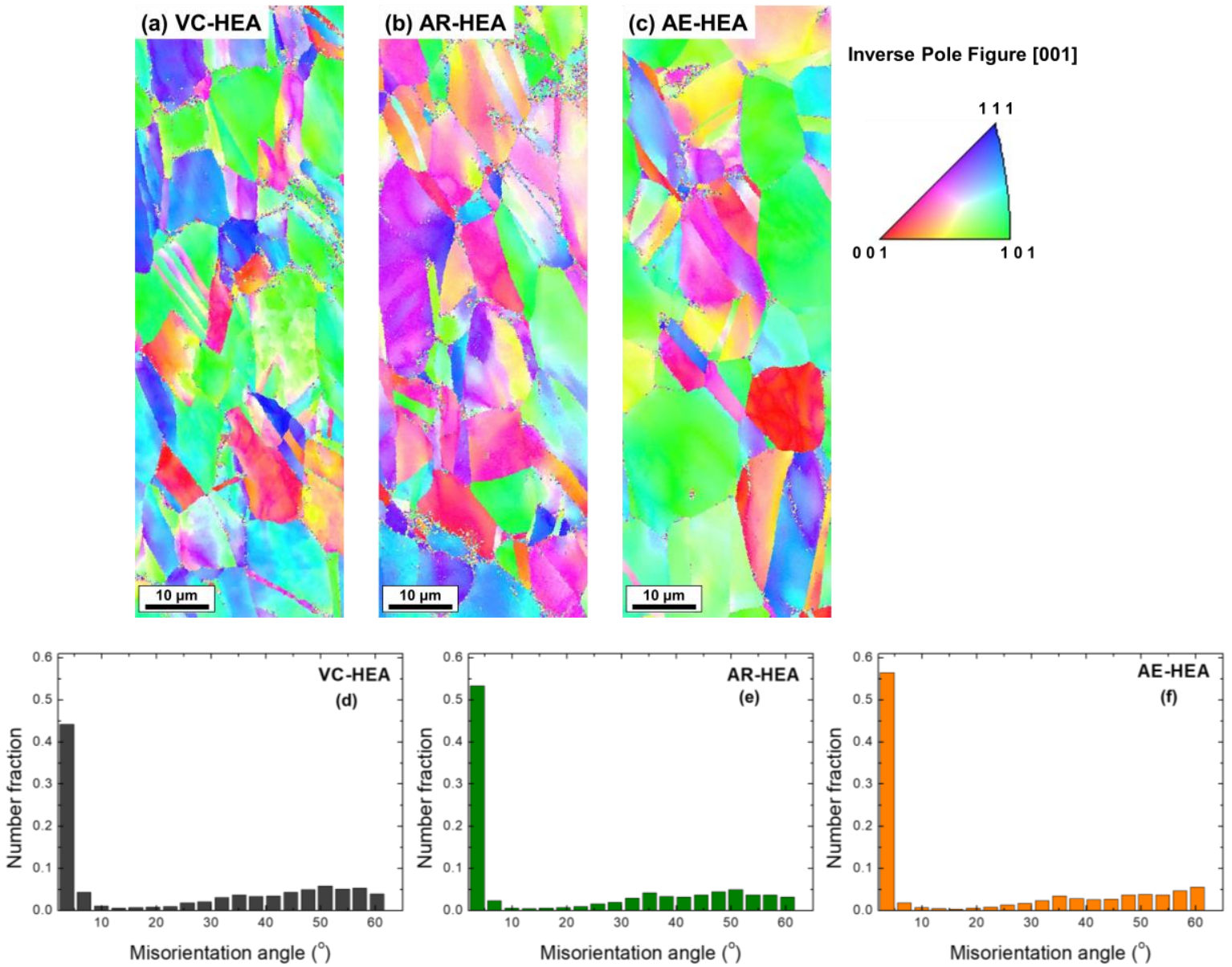

Figure 10. $(\mathbf{a}-\mathbf{c})$ Microstructure of the HEAs after ductile fracture. (d-f) Misorientation distribution of the HEAs.

\section{Discussion}

Tervo et al. [54] reported that an increase in the impurity content causes a difference in the absolute number of inclusions as well as the fraction of coarse inclusions. An increased number of coarse inclusions leads to a much higher area fraction of particles. Commercial grade raw materials with a purity greater than $99.9 \%$ could be used for the manufacturing of high-entropy alloys. Nevertheless, the contamination of interstitial elements such as $\mathrm{O}, \mathrm{S}, \mathrm{N}$, etc. as well as substitutional impurities such as $\mathrm{Al}$ is inevitable, as shown in previous section (Tables 1 and 2). 
In general, the characteristics of non-metallic inclusions such as size, composition, morphology, and area/volume fractions are known to have an influence on the chemical and mechanical properties of alloys and steels [16,26-32,37,61]. As the three HEAs in the present study have different impurity levels, the chemistry, size, and area fraction of the inclusion particles are subsequently different. As discussed in the previous section (Figures 5 and 6), AE-HEA contains the smallest inclusions consisting of $\mathrm{MnCr}_{2} \mathrm{O}_{4}$ spinel, while AR-HEA and VC-HEA contain large size $\mathrm{Al}_{2} \mathrm{O}_{3}$ particles. Moreover, VC-HEA has the highest impurity level and contains the largest inclusions.

Herewith, we can discuss the relationship between the mechanical properties of the HEA and the size and composition of inclusions in each alloy sample. As VC-HEA contains the largest inclusions, the volume fraction of particles is also the highest. According to previous researchers, the toughness of metallic materials could be degraded as the inclusion size and volume fraction increases [27,37]. In addition, the composition of inclusions is another factor affecting the mechanical properties, because the physicochemical properties of the inclusions themselves also vary as a function of the chemical composition. It is known that brittle inclusion particles in a ductile matrix become an initiation site for the generation and propagation of cracks [62]. The hardness values of $\alpha-\mathrm{Al}_{2} \mathrm{O}_{3}$ corundum and manganochromite $\left(\mathrm{MnCr}_{2} \mathrm{O}_{4}\right)$ spinel are 13.4-15.7 GPa and about 9.8 GPa, respectively [63,64]. The harder and brittle $\mathrm{Al}_{2} \mathrm{O}_{3}$ inclusions potentially tend to generate more cracks and are much more deleterious than $\mathrm{MnCr}_{2} \mathrm{O}_{4}$ inclusions in an FCC matrix. Thus, the highest YS and UTS values of AE-HEA are also related to the size and composition of inclusions (Figure 7a).

Due to the higher dislocation density around inclusion particles, the flow stress increases and the strain hardening capacity decreases in AE-HEA. As shown in Figure $7 \mathrm{~b}$, the strain hardening rate of the AE-HEA is slightly higher than the other two alloys at the strain level below 0.25 of true strain. This indicates a possible beneficial role of fine inclusions in AE-HEA to cause an enhanced strain hardening due to dislocation entanglements around the small rigid particles (Figure 9c). However, at the later stage of deformation above 0.25 of the true strain, the local stress concentrations around the fine inclusions could result in earlier fractures compared to the other two alloys. Meanwhile, further developments of deformation twinning in AE-HEA enhance the strain hardening. Contrary to coarse inclusion particles, fine particles could enhance strain hardening by dislocation multiplication around the particles, which is also observed in the present study (Figure 9c) [65-67].

The relationship between experimental mechanical properties (UTS, $\varepsilon_{f}$ ) and area fraction of total inclusions is shown in Figure 11. The UTS values decrease as the area fraction of inclusion increases. As mentioned before, larger inclusions became initiation sites for crack generation and fine inclusions contributed to the enhancement of strength by delaying the movement of dislocation. VC-HEA shows the lowest tensile strength (UTS = $620 \mathrm{MPa}$ ) due to the negative influence of large and brittle $\mathrm{Al}_{2} \mathrm{O}_{3}$ particles. AR-HEA, which contains less coarse $\mathrm{Al}_{2} \mathrm{O}_{3}$ particles, shows similar tensile properties but slightly higher strength (UTS $=625 \mathrm{MPa}$ ) than $\mathrm{VC}-\mathrm{HEA} . \mathrm{Al}_{2} \mathrm{O}_{3}$ inclusions are known to have a significant influence on fatigue properties of steels, and large inclusions cause an easy exfoliation of a matrix along the interfacial area between the matrix and inclusions due to the larger surface area [68,69]. The main type of inclusions in AE-HEA was $\mathrm{MnCr}_{2} \mathrm{O}_{4}$ (mainly $1 \mu \mathrm{m}$ or less), which is less deleterious for crack initiation (less hardness, smaller size). Instead, these particles caused an extra strengthening of the alloy by dislocation pinning around them. Consequently, the tensile strength increased to about $670 \mathrm{MPa}$, but the elongation to fracture decreased. 


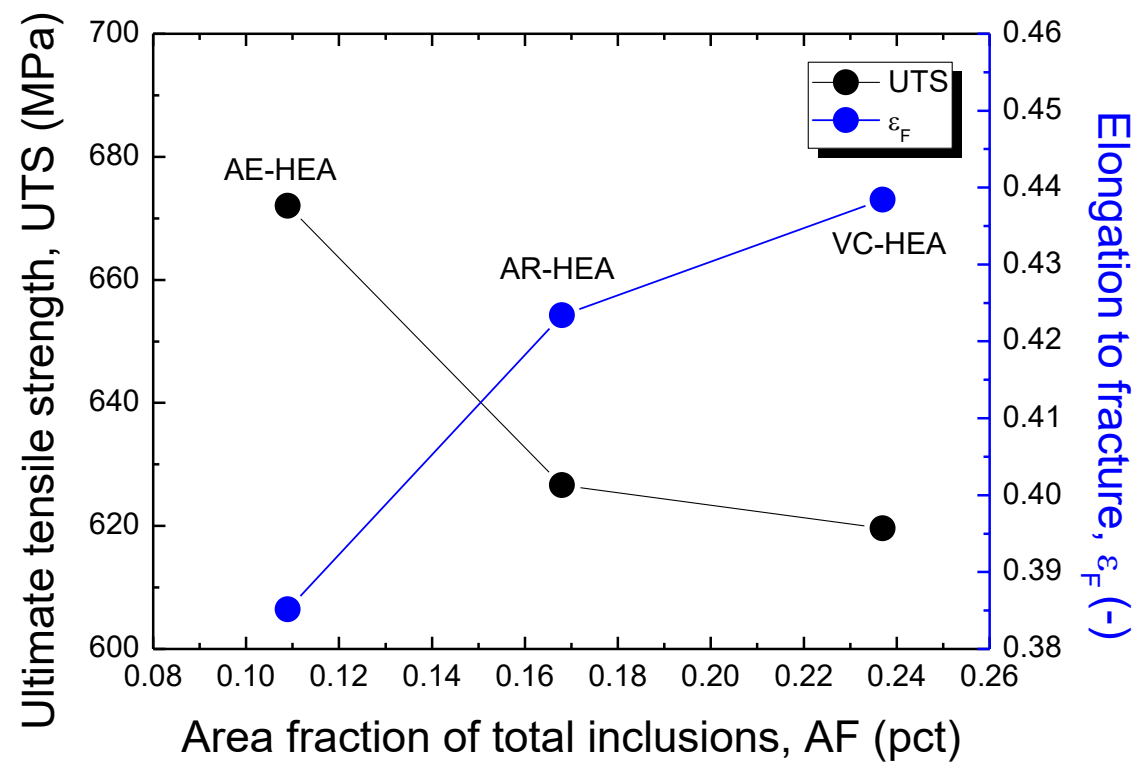

Figure 11. Comparison of ultimate tensile strength (UTS) and elongation to fracture $\left(\varepsilon_{\mathrm{f}}\right)$ of HEAs according to the area fraction of total inclusions.

\section{Conclusions}

In the present study, equiatomic FeCrNiMnCo alloys were manufactured according to different atmospheric conditions: (i) vacuum melting, (ii) induction melting under a purified Ar atmosphere, and (iii) induction melting under an Ar atmosphere, followed by an air exposure. A beneficial role of an external oxidation, resulting in the removal of impurities (specifically $\mathrm{Al}$ ) contaminated from the raw materials, was experimentally confirmed. Thus, the impurity contents and characteristics of inclusions were varied depending upon the manufacturing conditions of HEA. The alloys melted under vacuum or using an inert gas atmosphere contained relatively large $\mathrm{Al}_{2} \mathrm{O}_{3}$ particles, which had been formed due to the high affinity between aluminum and oxygen. In the alloy melted under a purified Ar atmosphere, followed by an air exposure, $\mathrm{Al}$ was primarily oxidized, which resulted in the formation of relatively fine $\mathrm{MnCr}_{2} \mathrm{O}_{4}$ particles rather than coarse $\mathrm{Al}_{2} \mathrm{O}_{3}$ inclusions. The fine inclusions in the AE-HEA led to an increased yield strength and enhanced strain hardening as well as the activation of deformation twinning. Consequently, it is proposed that the use of atmospheric conditions affects the inclusion characteristics in a positive manner, since the resulting fine inclusion particles could improve the mechanical properties of HEA.

Author Contributions: Conceptualization, J.H.P.; methodology, N.C. and J.H.P.; software, N.C.; validation, N.C., N.P., J.-k.K., A.V.K., P.G.J. and J.H.P.; formal analysis, N.C., J.-k.K. and J.H.P.; investigation, N.C. and J.-k.K.; data curation, N.C., J.-k.K. and J.H.P.; writing—original draft preparation, N.C.; writing-review and editing, N.P., J.-k.K., A.V.K., P.G.J. and J.H.P.; visualization, N.C.; supervision, J.-k.K. and J.H.P.; project administration, J.H.P.; funding acquisition, J.H.P. All authors have read and agreed to the published version of the manuscript.

Funding: This research was supported by the Basic Science Research Program through the National Research Foundation of Korea (NRF) funded by the Ministry of Education (Grant number NRF-2018R1A2B6005809). Also, this work was supported by LG Yonam Foundation, Korea.

Conflicts of Interest: The authors declare no conflict of interest.

\section{References}

1. Yeh, J.W.; Chen, S.K.; Lin, S.J.; Gan, J.Y.; Chin, T.S.; Shun, T.T.; Tsau, C.H.; Chang, S.Y. Nanostructured high-entropy alloys with multiple principal elements: Novel alloy design concepts and outcomes. Adv. Eng. Mater. 2004, 6, 299-303. [CrossRef]

2. Cantor, B.; Chang, I.T.H.; Knight, P.; Vincent, A.J.B. Microstructural development in equiatomic multicomponent alloys. Mater. Sci. Eng. A 2004, 375, 213-218. [CrossRef] 
3. Zhang, F.; Zhang, C.; Chen, S.L.; Zhu, J.; Cao, W.S.; Kattner, U.R. An understanding of high entropy alloys from phase diagram calculations. Calphad 2014, 45,1-10. [CrossRef]

4. Haglund, A.; Koehler, M.; Catoor, D.; George, E.P.; Keppens, V. Polycrystalline elastic moduli of a high-entropy alloy at cryogenic temperatures. Intermetallics 2015, 58, 62-64. [CrossRef]

5. Tsai, M.H.; Yeh, J.W. High-entropy alloys: a critical review. Mater. Res. Lett. 2014, 2, 107-123. [CrossRef]

6. Ye, Y.F.; Wang, Q.; Lu, J.; Liu, C.T.; Yang, Y. High-entropy alloy: challenges and prospects. Mater. Today 2016, 19, 349-362. [CrossRef]

7. Raabe, D.; Tasan, C.C.; Springer, H.; Bausch, M. From high-entropy alloys to high-entropy steels. Steel Res. Int. 2015, 86, 1127-1138. [CrossRef]

8. Otto, F.; Dlouhý, A.; Somsen, C.; Bei, H.; Eggeler, G.; George, E.P. The influences of temperature and microstructure on the tensile properties of a CoCrFeMnNi high-entropy alloy. Acta Mater. 2013, 61, 5743-5755. [CrossRef]

9. Gludovatz, B.; Hohenwarter, A.; Catoor, D.; Chang, E.H.; George, E.P.; Ritchie, R. A fracture-resistant high-entropy alloy for cryogenic applications. Science 2014, 345, 1153-1158. [CrossRef]

10. Joo, S.H.; Kato, H.; Jang, M.J.; Moon, J.; Tsai, C.W.; Yeh, J.W.; Kim, H.S. Tensile deformation behavior and deformation twinning of an equimolar CoCrFeMnNi high-entropy alloy. Mater. Sci. Eng. A 2017, 689, 122-133. [CrossRef]

11. Mizumachi, S.; Koyama, M.; Fukushima, Y.; Tsuzaki, K. Growth behavior of a mechanically long fatigue crack in an FeCrNiMnCo high entropy alloy: A comparison with an austenitic stainless steel. ISIJ Int. 2020, 60, 175-181. [CrossRef]

12. Huang, S.; Li, W.; Lu, S.; Tian, F.; Shen, J.; Holmström, E.; Vitos, L. Temperature dependent stacking fault energy of FeCrCoNiMn high entropy alloy. Scr. Mater. 2015, 108, 44-47. [CrossRef]

13. Liu, W.H.; Wu, Y.; He, J.Y.; Nieh, T.G.; Lu, Z.P. Grain growth and the Hall-Petch relationship in a high-entropy FeCrNiCoMn alloy. Scr. Mater. 2013, 68, 526-529. [CrossRef]

14. Wu, Z.; Parish, C.M.; Bei, H. Nano-twin mediated plasticity in carbon-containing FeNiCoCrMn high entropy alloys. J. Alloys Compd. 2015, 647, 815-822. [CrossRef]

15. He, J.Y.; Wang, H.; Huang, H.L.; Xu, X.D.; Chen, M.W.; Wu, Y.; Liu, X.J.; Nieh, T.G.; An, K.; Lu, Z.P. A precipitation-hardened high-entropy alloy with outstanding tensile properties. Acta Mater. 2016, 102, 187-196. [CrossRef]

16. Thornto, P.A. The influence of nonmetallic inclusions on the mechanical properties of steel: A review. J. Mater. Sci. 1971, 6, 347-356. [CrossRef]

17. Umezawa, O.; Nagai, K. Effects of test temperature on internal fatigue crack generation associated with nonmetallic particles in austenitic steels. Metall. Mater. Trans. A 1998, 29A, 3017-3028. [CrossRef]

18. Webb, E.G.; Suter, T.; Alkire, R.C. Microelectrochemical measurements of the dissolution of single MnS inclusions, and the prediction of the critical conditions for pit initiation on stainless steel. J. Electrochem. Soc. 2001, 148, B186-B195. [CrossRef]

19. Yang, C.L.; Zhang, Z.J.; Zhang, P.; Zhang, Z.F. The premature necking of twinning-induced plasticity steels. Acta Mater. 2017, 136, 1-10. [CrossRef]

20. Jablonski, P.D.; Licavoli, J.J.; Gao, M.C.; Hawk, J.A. Manufacturing of high entropy alloys. JOM 2015, 67, 2278-2287. [CrossRef]

21. Licavoli, J.J.; Gao, M.C.; Sears, J.S.; Jablonski, P.D.; Hawk, J.A. Microstructure and mechanical behavior of high-entropy alloys. J. Mater. Eng. Perform. 2015, 24, 3685-3698. [CrossRef]

22. Gludovatz, B.; George, E.P.; Ritchie, R.O. Processing, Microstructure and mechanical properties of the CrMnFeCoNi high-entropy alloy. JOM 2015, 67, 2262-2270. [CrossRef]

23. Gali, A.; George, E.P. Tensile properties of high- and medium-entropy alloys. Intermetallics 2013, 39, 74-78. [CrossRef]

24. He, J.Y.; Zhu, C.; Zhou, D.Q.; Liu, W.H.; Nieh, T.G.; Lu, Z.P. Steady state flow of the FeCoNiCrMn high entropy alloy at elevated temperatures. Intermetallics 2014, 55, 9-14. [CrossRef]

25. Schuh, B.; Martin, F.M.; Völker, B.; George, E.P.; Clemens, H.; Pippan, R.; Hohenwarter, A. Mechanical properties, microstructure and thermal stability of a nanocrystalline CoCrFeMnNi high-entropy alloy after severe plastic deformation. Acta Mater. 2015, 96, 258-268. [CrossRef]

26. Wu, C.Z.; Shih, T.S. Effects of inclusion particles on the microstructure and mechanical properties of high strength austempered ductile iron. Mater. Trans. 2003, 44, 995-1003. [CrossRef] 
27. Yakura, R.; Matsuda, M.; Sakai, T.; Ueno, A. Effect of inclusion size on fatigue properties in very high cycle region of low alloy steel used for solid type crankshaft. Kobleco Technol. Rev. 2017, 35, 7-13.

28. Li, W.; Deng, H.; Liu, P. Interior fracture mechanism analysis and fatigue life prediction of surface-hardened gear steel under axial loading. Materials 2016, 9, 843. [CrossRef]

29. Srivastava, A.; Ponson, L.; Osovski, S.; Bouchaud, E.; Tvergaard, V.; Needleman, A. Effect of inclusion density on ductile fracture toughness and roughness. J. Mech. Phys. Solids 2014, 63, 62-79. [CrossRef]

30. Hill, D.C.; Passoja, D. Understanding the role of inclusions and microstructure in ductile fracture. Weld. Res. Suppl. 1974, 53, 481-485.

31. Urbano, M.F.; Cadelli, A.; Sczerzenie, F.; Luccarelli, P.; Beretta, S.; Coda, A. Inclusions size-based fatigue life prediction model of NiTi alloy for biomedical applications. Shape Mem. Superplast. 2015, 1, 240-251. [CrossRef]

32. Ånmark, N.; Karasev, A.V.; Jonsson, P.G. The effect of different non-metallic inclusions on the machinability of steels. Materials 2015, 8, 751-783. [CrossRef] [PubMed]

33. Park, J.H.; Kang, Y. Inclusions in Stainless Steels-A Review. Steel Res. Int. 2017, 88, 1700130. [CrossRef]

34. Kiessling, R.; Lange, N. Non-Metallic Inclusions in Steel; Metals Society: London, UK, 1978.

35. Ånmark, N.; Björk, T.; Ganea, A.; Ölund, P.; Hogmark, S.; Karasev, A.V.; Jönsson, P.G. The effect of inclusion composition on tool wear in hard part turning using PCBN cutting tools. Wear 2015, 334, 13-22. [CrossRef]

36. Choi, N.; Lim, K.R.; Na, Y.S.; Glatzel, U.; Park, J.H. Characterization of non-metallic inclusions and their influence on the mechanical properties of a FCC single-phase high-entropy alloy. J. Alloys Compd. 2018, 763, 546-557. [CrossRef]

37. Garrison, W.M.; Wojcieszynski, A.L. A discussion of the effect of inclusion volume fraction on the toughness of steel. Mater. Sci. Eng. A 2007, 464, 321-329. [CrossRef]

38. Park, N.; Lee, B.J.; Tsuji, N. The phase stability of equiatomic CoCrFeMnNi high-entropy alloy: comparison between experiment and calculation results. J. Alloys Compd. 2017, 719, 189-193. [CrossRef]

39. Choi, W.M.; Jung, S.; Jo, Y.H.; Lee, S.; Lee, B.J. Design of new face-centered cubic high entropy alloys by thermodynamic calculation. Met. Mater. Int. 2017, 23, 839-847. [CrossRef]

40. ASTM E 8/E8M-09, Standard Test Methods for Tension Testing of Metallic Materials; ASTM International: West Conshohocken, PA, USA, 2009.

41. Max, S. Process for the Production of Nickel and Cobalt Alloys by Aluminothermic Reduction. U.S. Patent No. 2,270,643, 20 January 1942.

42. Yoshitaka, K.; Yang, J.; Liu, Z.; Kuwabara, M. Mechanism of aluminothermic reduction of chromium oxide. J. High Temp. Soc. 2009, 34, 20-25. [CrossRef]

43. Martirosyan, V.; Torosyan, G.; Sasuntsyan, M.; Torosyan, N. Obtaining of ferrosilicochromium alloy by silicothermic reduction of the tapasar chromites and slags of copper casting factories. Meridian Eng. 2012, 2, 68-72.

44. Fan, X.; Xi, S.; Sun, D.; Liu, Z.; Du, J.; Tao, C. Mn-Se interactions at the cathode interface during the electrolytic-manganese process. Hydrometallurgy 2012, 127-128, 24-29. [CrossRef]

45. Park, J.H.; Kim, D.J.; Min, D.J. Characterization of nonmetallic inclusions in high-manganese and aluminum-alloyed austenitic steels. Metall. Mater. Trans. A 2012, 43A, 2316-2324. [CrossRef]

46. Bracq, G.; Brocq, M.L.; Perrière, L.; Pirès, R.; Joubert, J.M.; Guillot, I. The fcc solid solution stability in the Co-Cr-Fe-Mn-Ni multi-component system. Acta Mater. 2017, 128, 327-336. [CrossRef]

47. Gaskell, D.R.; Laughlin, D.E. Introduction to the Thermodynamics of Materials; CRC Press, Taylor and Francis Group: Boca Raton, FL, USA, 2017.

48. Pickering, E.J.; Moreno, R.M.; Stone, H.J.; Jones, N.G. Precipitation in the equiatomic high-entropy alloy CrMnFeCoNi. Scr. Mater. 2016, 113, 106-109. [CrossRef]

49. Park, J.S.; Park, J.H. Effect of Mg-Ti deoxidation on the formation behavior of equiaxed crystals during rapid solidification of iron alloys. Steel Res. Int. 2014, 85, 1303-1309. [CrossRef]

50. Lee, M.H.; Park, J.H. Synergistic effect of nitrogen and refractory material on TiN formation and equiaxed grain structure of ferritic stainless steel. Metall. Mater. Trans. B 2018, 49B, 877-893. [CrossRef]

51. Kwon, S.K.; Park, J.S.; Park, J.H. Influence of refractory-steel interfacial reaction on the formation behavior of inclusions in Ce-containing stainless steel. ISIJ Int. 2015, 55, 2589-2596. [CrossRef]

52. Kwon, S.K.; Kong, Y.M.; Park, J.H. Effect of Al deoxidation on the formation behavior of inclusions in Ce-added stainless steel melt. Met. Mater. Int. 2014, 20, 959-966. [CrossRef] 
53. Shin, J.H.; Park, J.H. Effect of $\mathrm{CaO} / \mathrm{Al}_{2} \mathrm{O}_{3}$ ratio of ladle slag on formation behavior of inclusions in $\mathrm{Mn}$ and $\mathrm{V}$ alloyed steel. ISIJ Int. 2018, 58, 88-97. [CrossRef]

54. Tervo, H.; Kaijalainen, A.; Pikkarainen, T.; Mehtonen, S.; Porter, D. Effect of impurity level and inclusions on the ductility and toughness of an ultra-high-strength steel. Mater. Sci. Eng. A 2017, 697, 184-193. [CrossRef]

55. Gludovatz, B.; Hohenwarter, A.; Thurston, K.V.S.; Bei, H.; Wu, Z.; George, E.P.; Ritchie, R.O. Exceptional damage-tolerance of a medium-entropy alloy CrCoNi at cryogenic temperatures. Nat. Commun. 2016, 7, 10602. [CrossRef]

56. Goodwin, S.J.; Noble, F.W.; Eyre, B.L. Inclusion nucleated ductile fracture in stainless steel. Acta Metall. 1989, 37, 1389-1398. [CrossRef]

57. Eshelby, J.D.; Peierls, R.E. The determination of the elastic field of an ellipsoidal inclusion, and related problems. Math. Phys. Sci. 1957, 241, 376-396.

58. Eshelby, J.D.; Peierls, R.E. The elastic field outside an ellipsoidal inclusion. Math. Phys. Sci. 1959, 252, 561-569.

59. Simmons, J.A.; deWit, R.; Bullough, R. Fundamental Aspects of Dislocation Theory Conference Proceedings; National Bureau of Standards: Gaithersburg, MD, USA, 1970.

60. Kords, C. On the Role of Dislocation Transport in the Constitutive Description of Crystal Plasticity. Ph.D. Thesis, RWTH Aachen University, Aachen, Germany, 2013.

61. Reformatskaya, I.I.; Freiman, L.I. Precipitation of sulfide inclusions in steel structure and their effect on local corrosion processes. Prot. Met. 2001, 37, 459-464. [CrossRef]

62. Horstemeyer, M.F.; Gokhale, A.M. A void-crack nucleation model for ductile metals. Int. J. Solids Struct. 1999, 36, 5029-5055. [CrossRef]

63. Wefers, K.; Misra, C. Oxides and Hydroxides of Aluminum; Alcoa Laboratories, Aluminum Company of America: Pittsburg, PA, USA, 1987.

64. Anthony, J.W.; Bideaux, R.A.; Bladh, K.W.; Nichols, M.C. Handbook of Mineralogy; Mineral Data Publ.: Tucson, AZ, USA, 1990.

65. Kim, Y.K.; Choe, J.; Lee, K.A. Selective laser melted equiatomic CoCrFeMnNi high-entropy alloy: microstructure, anisotropic mechanical response, and multiple strengthening mechanism. J. Alloys Compd. 2019, 805, 680-691. [CrossRef]

66. AlMangour, B.; Kim, Y.K.; Grzesiak, D.; Lee, K.A. Novel TiB 2 -reinforced 316L stainless steel nanocomposites with excellent room- and high-temperature yield strength developed by additive manufacturing. Compos. Part B Eng. 2019, 156, 51-63. [CrossRef]

67. Queyreau, S.; Monnet, G.; Devincre, B. Orowan strengthening and forest hardening superposition examined by dislocation dynamics simulations. Acta Mater. 2010, 58, 5586-5595. [CrossRef]

68. Bi, Y.; Karasev, A.V.; Jönsson, P.G. Three-dimensional investigations of inclusions in ferroalloys. Steel Res. Int. 2014, 85, 659-669. [CrossRef]

69. Ånmark, N.; Karasev, A.V.; Jönsson, P.G. The influence of microstructure and non-Metallic inclusions on the machinability of clean steels. Steel Res. Int. 2016, 88, 1600111. [CrossRef]

(C) 2020 by the authors. Licensee MDPI, Basel, Switzerland. This article is an open access article distributed under the terms and conditions of the Creative Commons Attribution (CC BY) license (http://creativecommons.org/licenses/by/4.0/). 